\title{
E-Government 4.o: Managing APIs as Facilitators for Digital Transformation
}

\author{
Denis Trček \\ Faculty of Computer and Information Science, \\ University of Ljubljana, \\ Večna pot 113, 1000 Ljubljana, Slovenia
}

DOI: https://doi.org/10.36941/ajis-2022-ooo1

\begin{abstract}
Digital transformation is, among others, notably driven by servitization, and consequently, IT artifacts called Application Programming Interfaces (APIs), together with disruptive technologies and innovations. In order to set up proper policies, the understanding of the above factors is essential, including their influences on value adding chains. This paper therefore provides an analysis of APIs developments together with their impacts on digital transformation. As they can affect organizations and even national economies at strategic level, appropriate management from a systemic perspective is justified, including e-Government initiatives. Further, APIs cannot be treated without their relations to disruptive technologies, innovations and value chains. Therefore, the advancements of theoretical understanding of evolution of value chains, and practical directions for e-government initiatives are given in this paper. In addition, an archetype model is developed that provides a basis for further research efforts in the area.
\end{abstract}

Keywords: digital transformation, servitization, application programming interfaces, innovation, disruptive technologies, value chains, e-government

\section{Introduction}

The spread of the Internet into the business world in the mid-nineties of the former century led to an increased digitalization of business processes - and the era of e-business was born. In the beginning, these digital transformation processes were mainly limited to non-tangible segments, ranging from office automation to electronic data interchange and e-commerce in general.

In recent years, these processes began to penetrate tangible goods segments and industrial and manufacturing segments. This development is considered a new industrial revolution and is referred to as Industry 4.o, which is a natural consequence of the developments that began with the ebusiness era. The key disruptive technologies in the background of this recent transition are big data, virtual (and augmented) reality, autonomous robots (cyber-physical systems in general), additive manufacturing, Internet of Things, cloud computing and cybersecurity (Westerman et al., 2014). In addition, concepts such as enterprise architectures, service-oriented architectures, and business process management are also crucial, even though they are often overlooked. No wonder, as there is a lack of powerful tools, including formal methods and system methods (Xu et al., 2018). In addition, understanding past developments is crucial to anticipate the course of developments and manage them accordingly. 
Although it may not seem so at first glance, but in the context of the disruptive technologies mentioned above, their integration is essential. This means access to data from numerous sources and to various services available via the web. To achieve this goal, application programming interfaces (or APIs for short) are a key player. APIs have already gained a lot of attention in recent years, but their role and potential are not yet fully recognized. Although APIs are a technological artifact, they have many non-technical implications that have yet to be explored (Wittern, 2018). These include the influences of APIs on businesses, not to mention the changes they help shape in digital markets (and societies in general), while current efforts mostly focus on the technology as such (Jin et al., 2018), (Higginbotham, 2015), (Berlind, 2019). Therefore, it is important to understand APIs and their involvement in relationships with innovation, disruptive technologies, and digital ecosystems in order to manage them properly. As mentioned earlier, this management needs to be underpinned by a formal, systemic approach, which is considered in this paper.

The key methodological approach used is system dynamics (Forrester, 1994), which is an established methodology. It seeks to understand and improve systems, which begins with the interpretation of the real world into a model description through stages. First, the description leads to the identification of core variables, their nature, and their interrelationships, resulting in what are called qualitative models. Next, these models are usually developed into quantitative models, backed by equations that enable simulations to understand the dynamic behavior and policies evaluation. As a basis for these steps, approaches range from systematic literature review to specialized techniques such as group model building, a participatory approach in which experts and practitioners are guided to create the desired model in a systemic manner (Hernantes et al., 2012). In addition to system dynamics, a minor part of the paper employs descriptive research, which describes the characteristics of the phenomenon under study and focuses more on the "what" than the "why" of the research subject.

The paper is organized as follows. In the second section, a literature review is given with an evolutionary view of the field. In the third section, the methodological part is carried out - APIs are further elaborated in order to understand and properly classify their developments within the field they belong to. In the fourth section, where the first part of the contributions is presented, important conceptual changes in value chains are addressed, which are also caused by APIs. This is followed by the second part of the contributions - an archetype model of digital services ecosystems based on system dynamics is presented to provide new insights and a better understanding of the area. In the sixth section, there is a discussion followed by future research directions. In the last section, there are conclusions, followed by acknowledgements and references.

\section{Overview of the Field}

Digital transformation has become a hot issue in recent years. It refers to many topics, concepts and technologies that connect business, government, and industries with information technology, and servitization developments (i.e. digital transformation of services). Understanding these issues is therefore important to predict the course of developments and to shape policy accordingly. The EU Commission recognized the impact of these processes as early as in year 2000 and adopted the ECommerce Directive, which provides the legal basis for digital services (Rodríguez de las Heras Ballell, 2021).

The digital transformation first took place in the non-material segments, as it was easier to do so there. One of the first industries to be affected were the film and music industries (Itten et al., 2020), with the music industry being particularly affected and forced to innovate to adapt to the changes - see e.g., (Sun, 2019) for the details about innovation processes behind the developments of digital music services.

The growing presence of the internet enabled further servitization, which has recently become a reality in material (manufacturing) sectors with Industry 4.o. Servitization is so important because it adds value to both customers and production processes (Frank et al., 2019). It brings a new dynamic 
to service provider-customer interactions through its impact on service delivery processes (Romero et al., 2019). "Servitization developments" also stimulated the involvement of small and medium-sized enterprises, which began to play an active role in the innovation processes of value chains (Rothgang \& Duerig, 2020). It is not surprising that digital transformation is also having a particular impact on value and supply chains internationally, as evidenced by changing intra- and inter-organizational relationships (Walters \& Helman, 2020), (Sabri et al., 2018). A more in-depth review of the concepts of servitization and product-service systems can be found in (Annarelli et al., 2019).

A main reason for the influence of servitization is that digital transformation enables efficient information flows to control chains in Industry 4.o (Tomanek et al., 2020). Administration should not be an exception in these integration efforts (Zaramenskikh \& Lyubarskaya, 2020), and its efforts should be the subject of continuous innovation processes - innovation system factors for this case are elaborated in (Zygiaris, 2021). The changes are considerable, so digital service innovation is now a mandatory topic, which is even considered a new business area (Eckert \& Huesig, 2021). This was proven during the recent Covid closures, when service innovations (using digital technologies) proved their importance and led to advances in the theory of service innovations (Tuomi et al., 2021).

Nowadays, disruptive technologies are becoming the focus of the above processes. To mention just a few interesting recent examples, we start with value chains where blockchains can be treated as a kind of (value) chain transformer, enabling the transfer of value over the Internet without intermediaries (Eggrickx et al., 2020). Interesting further developments also include applications in customer advisory support, where current AI approaches are expected to become anthropocentric (Kulkarni \& Dambe, 2020).

A key player in these processes are clearly governments, so it is important that their governance principles and policies are well prepared. Open data initiatives have been shown to play an important role in governments' efforts. New innovation practices, service development models, and collaborative environments are needed to successfully leverage open data. Appropriate ecosystems need to be established, and data quality is a key concern (Immonen et al., 2018). The success of egovernment initiatives also depends on how changes in decision-making environments can improve their adoption (Schneider et al., 2020). Furthermore, e-government services (and open data) require addressing specific perspectives. Therefore, a multidimensional perspective is presented in (Distel \& Lindgren, 2019), where the citizen is considered as a multi-layered and heterogeneous being. User participation is also important - it is shown that co-creation of digital public services, where possible, can lead to better solutions and their adoption, including open data (Jarke, 2021).

Governments need to take a comprehensive view of developments, including efficient resource management and green agenda issues for sustainable development (Castro \& Lopes, 2021). Moreover, digital divide issues come into play here, encompassing more than just access to information and communication resources (Vassilakopoulou \& Hustad, 2021).

The overview provided so far presents some fairly elaborate research questions, but in a fragmented manner. A more compact, comprehensive view of the trajectory of developments can be provided by identifying the key eras in the field. E-government efforts began at the end of the previous century, shortly after the era of e-business was born. This e-government 1.0 era was characterized by the core functionality that the Internet enabled - the interoperability of digital services. Like the developments in business, the new services enabled intensive two-way communication and led to the e-government 2.0 era, which was characterized by open and participatory governance. The increasing power of artificial intelligence led to the era of egovernment 3.0, characterized by IT assisted (and increasingly automated) decision-making and complemented by data-intensive policymaking. In the background of these developments, one particular artifact plays an increasingly important role - that is Application Programming Interfaces, APIs.

The growing importance of APIs for governments has not gone unnoticed by international bodies such as the United Nations, the OECD and the EU Commission. In the case of the United Nations, it is interesting to note that their recent survey on e-government only briefly mentions APIs 
(Affairs, 2020). In the case of the OECD, while this organization clearly recognizes the potential of APIs, it provides almost nothing about their wider implications as facilitators of digital transformation and no conceptual tools or models that would enable an appropriate strategic approach (Forum on tax administration, 2019). In contrast, the EU Commission's document on APIs (Vaccari et al., 2020) is quite different, identifying APIs as key to accessing digital assets and facilitating digital transformation. As APIs strategies are crucial for digital ecosystems, the document provides a transformation roadmap for improving the efficiency and effectiveness of governments through the increased innovation potential of public services via APIs. Moreover, APIs also improve policymaking by facilitating access to virtually all relevant information needed at all stages of the policy process. However, the framework is more of a descriptive nature. As the authors note, quantitative outcomes (e.g., socioeconomic impacts) are difficult to analyze for a variety of reasons, including the relatively recent and infrequent adoption of API policies, the problems of finding available government APIs on the Internet, and the difficulty of objectively measuring API impacts.

And this is where the contributions of this paper come in. Although research in this area is extensive, the paper presents some important steps forward. We are currently witnessing the proliferation of disruptive technologies in e-government, in particular the emergence of Internet-ofThings technologies associated with the explosion of data and the emergence of blockchains (ledger technologies), while security and privacy issues are coming to the fore. So, the first step forward is to develop a model of what is possible at this stage of knowledge in the field. The model identifies the key elements and their relationships, in particular governance issues related to APIs, digital ecosystems, disruptive technologies and innovation. Furthermore, from a systemic perspective (due to feedback loops), it logically follows that APIs lead to a network structure in which value can not only be created but also reduced. One such example is the potential negative impact in terms of security and privacy - although at first sight an API adds value (such as statistical data accessible over many databases), it may at the same time reduce value for citizens due to security and privacy issues (e.g. by enabling attacks using advanced data analytics to identify individuals, their health status, etc.). Consequently, the second step is a reassessment of value chains that evolve into valuetransforming networks, and a corresponding reconceptualization is given. Last but not least, an interesting observation is presented regarding the Matthew effect, which is likely to be influenced by APIs - but this observation needs further investigation.

\section{From Technological Basics to Business Evolution of APIs}

Application programming interfaces are abstract boundaries between information technology artifacts that are intended to enable and simplify their interconnection. Therefore, API can be defined as a technological abstraction that allows one artifact to access resources of another artifact through well-defined procedures for making requests and getting responses (i.e., protocols), along with specifications of data elements required by these procedures. However, although these are technological artifacts, their impact goes far beyond technology and affects integration at the business process level, not to mention the possibility of new services that may even lead to new industries. Moreover, certain APIs have even triggered broader societal changes.

APIs have evolved in many forms. Originally, they were used in software development to access routines in libraries, but also to access hardware resources. Later, with the advent of operating systems, APIs were used extensively to access resources of local systems, including operating systemspecific resources. But with the advent of networks (and the web in general), they began to play a key role in accessing resources over the web. And this latest form, web-based APIs, are the ones that are the focus of this research paper.

An API can be specified quite easily using web technology. One can simply use a URL that provides a unique identification of a service (or data feed) along with the protocol for accessing it. A concrete example of an API is given below. The domain name with local system identification is api.census.gov/data/2012/ewks?, while access is via the HTTP protocol (Bureau, 2021). The rest of the 
URL string is used to identify the method and arguments for local operation along with the authentication key for accessing the service (this particular API provides some economy-wide statistics in the US): https://api.census.gov/data/2012/ewks?get=EMP,OPTAX\&for=state:*\&NAICS 2012=54\&key $=23 \ldots$ c91

The history of APIs as tools to enable business functions can be traced back to 2000 (Raconteur, 2017). At that time, cloud application provider Salesforce.com began offering its services by allowing users to share data between those services through APIs. Similarly, eBay also entered this area in year 2000. Another shift occurred in 2002, when Amazon offered its Amazon Web Services, which allowed third parties to integrate Amazon's features into their own Web services (in 2006, Amazon took another step, and since then Amazon Web Services have provided access to cloud-based resources). Around the same time, social networking giants entered the field: Flicker in 2004, followed by Facebook and Twitter in 2006, all of which APIs enabled further proliferation (and reach) of their respective social networking service providers. In 2007, Google entered the field, and one of the most successful and influential APIs was launched: Google Maps. As to the governments' APIs, they followed with some delay of a few years.

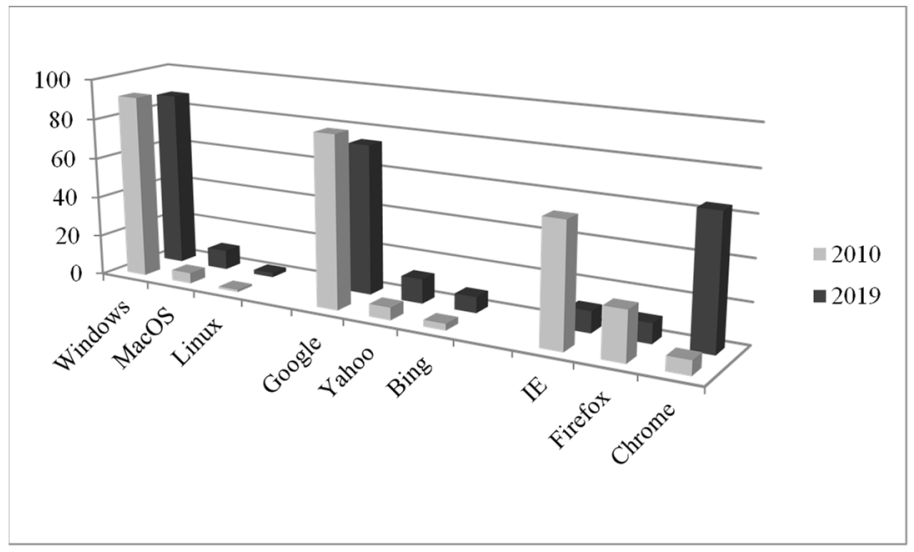

Figure 1: The distribution of key products and services

APIs can be considered as technological cousins of typical applications and services such as browsers, operating systems, search engines, etc. Looking at the evolution of these latter types of applications, important insights can be gained. For example, Figure 1 shows the data on the market share of three characteristic products and services, namely operating systems, web browsers and search engines.

It may be tempting to think that the above observations are only due to these typical products and services. However, a brief re-examination of the above observations with a different, newer and somewhat different type of service compared to the above, again confirms the identified observations. During the period from February 2018 to February 2019, Facebook's market share averaged over 70\%, followed by Pinterest with about $13 \%$, and this in turn is followed by Twitter and YouTube with about $6 \%$ market share each. So, predictably, social media market share also follows the same principles (see http://gs.statcounter.com/social-media-stats).

The above data is highly indicative. To articulate the principles in the background, a wellknown effect in the social sciences from the 196os, the so-called Matthew effect, can be used. It states that richer people get richer and poorer people get poorer. This observation is very related to (or based on) another observation by Pareto, about half a century older, stating that in many areas of human endeavor $80 \%$ of the effects come from $20 \%$ of the causes, also known as the $80 / 20$ rule.

However, digital transformation brings with it an additional momentum. Thus, this new 
situation could be called the ultra-Matthew effect or $80+/ 20$ rule - it may only take one player to capture (almost) 90\% of a market, but when this is not the case, the first two or three players are often enough to get close to or above that 90\%. However, the reader should note that this observation, while compelling, is still just an observation that needs further research.

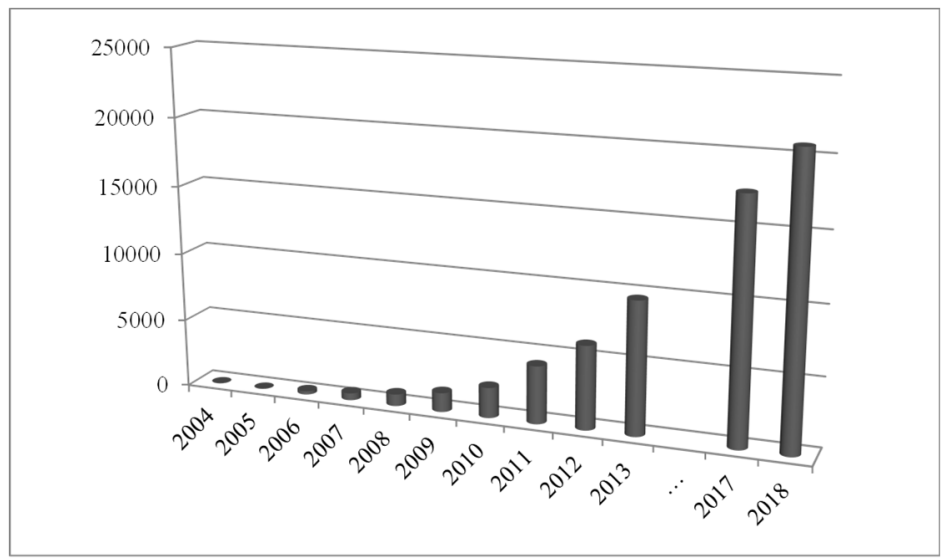

Figure 2: Growth of APIs during the last years (source programmableweb.com).

Can this observation be related to APIs? Let us first analyze the growth trends of APIs. Figure 2 shows that APIs are growing (almost) exponentially. It is expected that this trend will be the case for the foreseeable future. This is because the increasing number of IoT devices are becoming the main drivers of growth, including when it comes to data and services. According to Cisco's Visual Networking Index, more than 14 billion IoT devices are expected to emerge by 2022 (Gagliordi, 2019), and to harness their potential, APIs will be needed.

Second, APIs are closely related to the key products and services presented above, whose growth is shown in Fig. 1. Therefore, it makes sense to build on the experience with these key products and services, including when it comes to APIs. In doing so, APIs are not only growing at a remarkable pace, but a wide variety of application areas (categories) for them are emerging. These range from advertising and aggregation to government, semantic web, etc. - there are already several hundred such categories identified (see https://www.programmableweb.com/category/all/apis). It is worth noting that another repository of APIs shows an even higher growth: from January 2019 and January 2020 there was an increase from 17.4 million to 34.9 million, while in January 2021 the total number exceeded 46 million API collections. (Bettendorf, 2021).

So, we can expect some sort of $80+/ 20$ - consolidation in the API space as well. This may not be the case across the entire domain of APIs, but rather (at least initially) within specific categories. Recent research on the evolution of the APIs domain from 2005 to 2016 provides a supportive indication that this may be the case (Basole, 2019). The aforementioned research uses networks of APIs and their (statistics-based) analyzes, which include the number of nodes and edges, the average (weighted) degrees of the nodes, the diameter of the APIs network, its density, modularity, clustering, and average path length. The key message is that although the number of APIs is still growing, consolidation is already taking place. In this consolidation, the core APIs are becoming those of Google, Amazon Product Advertising, Facebook, YouTube, Twitter, and eBay. In particular, the Google Maps API plays an important role.

Based on the discussion so far, the novel contributions of this work will be presented in the next two sections. 


\section{Identifying Conceptual Shifts from Business Perspective}

When it comes to managing business (processes) in competitive market environments, a key strategic paradigm introduced by Porter in the 1980 s is the value chain. This revolutionary conceptualized management view reflected well the business reality for many decades.

However, about ten years later, the Internet began to penetrate the business world. Digital transformation impacted strategy and competition (Moore 1996), and the transformation of chains into value networks became a business reality. But as noted in (Basole 2019), pure chains are rare today. We need to talk about value networks (graphs). However, when it comes to APIs, it is not enough to think only about pure networks for the following reasons:

- In the case of APIs, feedback loops (especially those involving traditional end users) have emerged and are becoming increasingly important. Users are not just endpoints where data and services are consumed, but they are a part of feedback loops with these same sources of services and data. For example, when users use Google's services, Google also collects data from those same users (e.g., to improve its services).

- Consequently, in the case of networks with feedback loops that have emerged, value should not be considered only from the perspective of adding. It is not only the case that markets are not ideal, so that a reduction in value along a path in a value network is a reality, but also because a value is a matter of subjective judgment. Therefore, an increase in value in the perception of one consumer can mean a decrease in value in the perception of another consumer.

This new situation can be appropriately conceptualized with value transformation graphs and is shown in Fig. 3. The left side of the figure shows those feedback loops in which users are involved. However, API providers are also becoming increasingly connected in both directions, effectively creating networks where potentially any entity can be connected to another entity. In this way, cyclical paths are formed, and numerous feedback loops are created.

Also, from a systemic point of view, it is necessary to speak of value transformation networks (that add, preserve, reduce value) instead of supply chains, as will be elaborated in the next section.

\section{Systems Dynamics and Archetype Models for APIs Management}

Systems dynamics (also known as Business dynamics), which is now an established methodology, was developed in the early 1960 s by Jay Forrester (Porter, 1962). One of its central points is causal loops (i.e., feedback loops) that occur when observed variables are causally linked. These linkages can have positive polarity or negative polarity. A positive polarity means that increasing a driving variable increases the driven variable, while a negative polarity means that increasing a driving variable decreases the driven variable (and vice versa). The nature of feedback loops is determined by the polarities of the connections that make up these loops - loops can be reinforcing or balancing. As for variables, they can be material (e.g., people) or non-material (e.g., beliefs). In addition, they can be stocks, rates, and constants.

Once all variables are identified and properly linked, qualitative causal loop diagrams are obtained. They are intuitive, meaningful, and provide insight into the structure and functioning of a system. Moreover, they can be further elaborated to obtain quantitative models ready for simulations. This means that qualitative models must be appropriately backed up with formulas that quantify the variables and their relationships (Forrester 1961). 


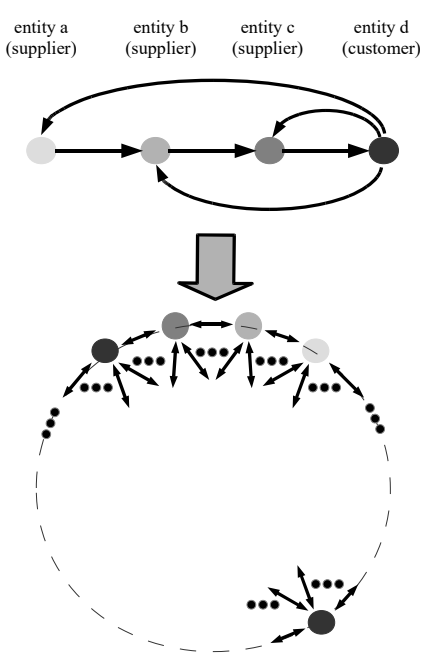

Figure 3: From feed-back loops affected value chains to value transforming networks.

System dynamics is particularly useful in the study of sociotechnical systems, where APIs and their ecosystems are a natural fit. To enable further application of system dynamics in this domain, archetype models are an established approach. Archetype models are qualitative models that are general in nature. They can be considered as template models with identified core variables and relationships, while serving as a starting point to obtain appropriate quantitative models (Gonzalez \& Trcek, 2017).

Based on the research in (Musser, 2013), (Narain et al., 2016), (Markets, 2017), (Gonzalez \& Trcek, 2017), (Trcek, 2018), an APIs ecosystem archetype model was developed that identifies the main elements related to current e-government transition processes and their relationships placed in a broader socio-economic perspective. This broader perspective is divided into three layers, which are the preconditions layer, the business models layer and the APIs consumption layer (see Fig. 4):

- Preconditions layer is the humus layer, where impacts are taking place. In the first place these are the results of enablers that are facilitated by drivers, where in the context of this paper enablers are primarily disruptive technologies and innovation. Further related to enablers, ubiquitous connections are a must, not only data and services as such that are offered on a market. Clearly, the enablers have to be available in a standardized way and with quality tools for the development of APIs. Further, in any transaction some level of trust must exist for this transaction to take place. Further, if these new creations have a potential to improve customers experience or internal processes, while being smoothly accessible, this will positively influence their market penetration. In order to achieve this goal, proper initiatives are needed as well. And finally, innovations. Their importance has been implicitly recognized so far by emphasizing the role of developers, which fit well into existing classifications, e.g. user-innovators as considered in (Pongtanalert \& Ogawa, 2015). But in the case of APIs, innovative thinking has to become a part of decision makers milieu (it can be stimulated thorough appropriate government initiatives). As to the drivers' impact, these are rather selfexplanationary and mostly in the domain of management.

- Once enablers and impacts are in place, APIs are being created and deployed externally (on a market) or internally (within an organization). Here, the potential of APIs becomes weighted against reality, i.e., users' needs. The higher these needs are, the larger the number of generated APIs (and vice versa). And this is what the business models layer is about. The richer the APIs market is, the higher the chances that the new innovative business practices, 
and even new business models will emerge due to the flexibility and modularity of APIs. There exist many such examples where new business models have already emerged thanks to APIs, and concrete cases can be especially found in the so-called collaborative economy (e.g., Uber).

- The final layer, the APIs consumption layer, is where the network of APIs consumers of all kinds takes place, i.e., where APIs are actually operationalized. This layer is no longer just about "traditional" end users because APIs are also connected to APIs through numerous feedback loops. So, this layer is about a network structure that transforms value accordingly. If sufficient value is created (more precisely, if the value added to a service exceeds its mitigation by negative effects), the needs of users further stimulate the growth of APIs. If insufficient value is added, the relevant part of the network begins to stagnate. This is where market forces make the final judgment on appropriate management approaches that take place within the first two layers.

Based on the given elaboration, let us now define APIs ecosystem(s). The Oxford dictionary defines ecosystem as complex network or interconnected system (in common usage). For marketoriented research (Moore 1996), ecosystems are defined as economic communities (producers, suppliers, competitors, and other stakeholders) "supported by a base of interacting organizations and individuals that produce goods and services of value to customers who are themselves members of the ecosystem." With further narrowing as given in (Basole 2019), ecosystem can be considered as a structure consisting of multiple firms that symbiotically create value. Therefore, the API ecosystem is a complex network in a digital market consisting of interconnected entities ranging from suppliers to customers that evolve around value transforming networks that are at the core of their processes.

\section{Discussion}

In the context of market growth and differentiation, the $80+/ 20$ observation, which should also determine the evolution of APIs ecosystems, is not the only observation that emerges from the study of this area. Another interesting observation is that whoever comes first is unlikely to gain a high enough number of early adopters to remain the first player but is likely to be displaced by players who come later. The first players seem to be a kind of "warm-up entities" for those who come next, and they take over the share according to the $80+/ 20-$ rule. While generalizing this observation would require additional research, there is quite a bit of case and evidence to support it:

- The popularity of web-based (cloud-based) email services is high. The first major and globally recognized provider was Hotmail. After many years, it was bought by Microsoft, but couldn't keep up with the newcomers, especially Google's Gmail. So a few years ago, Microsoft discontinued the original service, redesigned it noticeably, and replaced it with the Outlook service.

- In the social networking space as we know it today, the first major and globally recognized player was Second Life. But after the successful initial growth came new players, notably Facebook, which began to take the lead. And Facebook is still the leader today, while Second Life takes the role of a niche player.

- In the Internet search engine space, the first truly successful and globally recognized engine was Alta Vista (Archie and similar services existed before but were quite different at their core). It didn't take long for a new player to emerge (Google) that "took it all over". Microsoft has also dabbled in this area and remains visible with Bing, but Google is by far "the one and only".

- Looking at products, web browsers are the core. In the first half of the 1990s, this area was heavily dominated by Netscape, and remained so for years. But because of its strategic position in operating systems, Microsoft successfully attacked Netscape. MS Explorer became dominant, only to be beaten by Google Chrome a few years ago. Netscape no longer exists.

So, it is not surprising to see the above scenarios in the field of APIs as well. As mentioned 
earlier, the era of APIs began in 2000 when Salesforce made them available to users to access its services (Raconteur, 2017). Today, although the APIs ecosystem is growing significantly, Salesforce APIs are a marginal player. As indicated in (Basole 2019), the main APIs that have surfaced in recent years are those offered by players such as Google (especially Google Maps), Facebook, Twitter, Amazon Product Advertising, eBay, and YouTube (which is also part of Google).

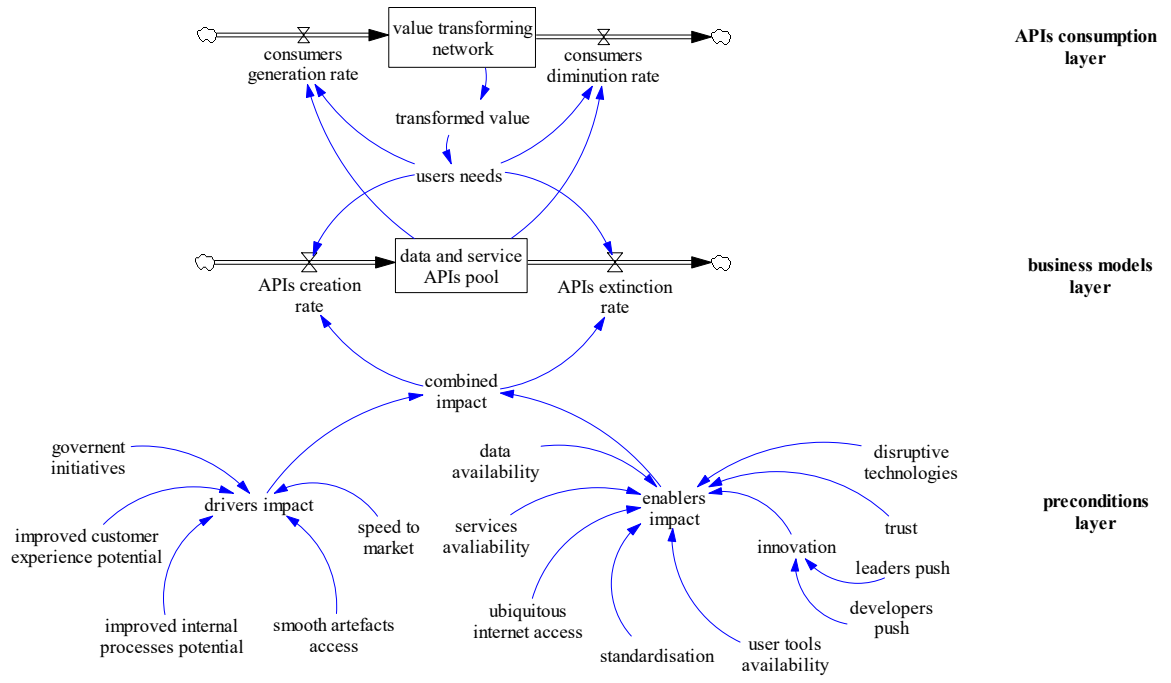

Figure 4: APIs ecosystem archetype model.

\section{Future Research Issues}

Changing the perspective and being now aware of the role of APIs in digital markets, many other important areas of future research (closely related to APIs) turn out to be important. Macroeconomic issues can be identified here, but even more so issues of security, privacy, safety and legal issues in general:

- From an economic perspective and anticipating the validity of the $80+/ 20$ observation, it can be expected that some kind of monopoly situation will emerge in the field of APIs (as mentioned, probably not across all APIs areas, but rather within areas). From a macroeconomic perspective, this leads to situations, which have long been known for their negative consequences on market development.

- From a security perspective - if an API is compromised by malicious actors, the entire ecosystem and its operations are compromised. Similarly, from a security perspective - if an API is accidentally compromised, the entire ecosystem of which it is a part and its operations will be compromised. To clarify the difference - in the case of security, a threat is the result of the activities of a malicious agent, while in the case of safety, a threat is the result of an unintended malfunction of an artifact or random conditions in its environment.

- Related to the critical aspects just mentioned is the issue of privacy. Since API ecosystems are typically highly interconnected and user data closes many loops, this poses a significant risk to user privacy if one or more APIs are compromised.

- Once you get into the issues of security, privacy, and safety, legal questions start to surface. Knowing that APIs will be behind many cyber-physical systems (such as autonomous vehicles), liability issues come to the fore. Current trends here look at the liability of the 
artificial intelligence engineers, the engineers of the device as such, the liability of the users, and the liability of third parties. If not further specified in the future, API developers and providers could fall into this fourth category.

- APIs (and business models they can drive) are expected to gain further momentum with the emergence of new technologies such as IoT and related architectures (Zhang et al., 2020). Effective deployment of these architectures without APIs is not realistic.

- Last but not least, and by combining the consequences of all the above, it is reasonable to assume that certain APIs will have strategic consequences (it is not difficult to draw parallels between GPS navigation system and Google Maps API). It is therefore to be expected that political strategic issues (such as national security) will also be identified in relation to APIs.

The above issues, while important, are beyond the scope of this article. However, it can be seen that system dynamics, which provides systemic insights into technical, social or socio-technical systems, is a promising method that can also be applied in these areas of APIs ecosystems.

To round off this section, additional attention should be paid to servitization. Servitization refers to another transformation related to manufacturing, where manufacturers move from delivering products only to delivering a combination of products and services. Complementary to Industry 4.o, which focuses on value creation in manufacturing, Servitization focuses on value creation for the customer. What is missing in this area are interfaces and connections between the two trends, and frameworks have been developed to bridge this gap (Frank et al, 2019). Knowing and understanding how technological artifacts such as APIs lead to organizational and societal change, it becomes clear that APIs also need to be seriously considered when managing the relationships (and interfaces) between servitization and Industry 4.o. The research presented in this paper with an archetype model based on system dynamics provides a good foundation for such efforts.

\section{Conclusions}

Since the beginning of e-business era in the mid-nineties of the former century, digital transformation has resulted in numerous changes that were almost impossible to predict even some twenty years ago. It turns out that many related processes are strongly linked to APIs, which are a kind of a hidden player behind these complex transformations. A likely reason is that APIs, being technological artifacts, have many important implications for businesses, which often have reflections even at the macroeconomic scale. But being short of appropriate powerful tools to manage latest e-business developments, in particular formal and system methods ( $\mathrm{Li} \mathrm{2018}$ ), this paper presents new systemic approaches to APIs and related ecosystems. These approaches help to understand the transition processes that pave the way towards e-government 4.o. By knowing that current eras include (a) interoperable digital services, (b) open and participatory government, and (c) automated decision making and data-intensive policy making, the visible advancements in ubiquitous integration and disruptive technologies deployment notably identify the future course of developments.

The paper starts with an overview of the developments in the area, followed by the technological basics of APIs, and then continues with the identification of core changes for businesses and digital markets. These changes are such that new models and certain reconceptualisations are needed to properly reflect the evolution that has taken place, and to provide appropriate management approaches. So, starting with the concept of value (added) chains introduced by Porter some forty years ago, it has been shown how these chains have evolved into interconnected structures and resulted in value networks. However, also APIs introduce numerous feed-back loops into these increasingly complex networks, so from the evolutionary, and systemic perspective, these networks are now more properly referred to as value transforming networks.

Recognizing the nature of these new structures is also important because of appropriate methodologies for their further analyses, where especially appropriate models are missing. So far, some formal research of APIs ecosystems has been done with statistics-based networks analyses. But 
it turns out that APIs are a natural fit for another methodology, which is System dynamics. This paper therefore presents an archetype model of APIs ecosystems to provide a top-down insight into their structure and functioning. The model is intended to spur more narrowly focused, quantitative research in this area for its better management and understanding, and to draw attention of key players to APIs. E-government initiatives, in particular, may play an important role here (Fang et al., 2015). They should focus on innovations, not only at the technological, but also organizations management level.

Summing up, APIs are too important to be insufficiently addressed, because they affect not only organizations, but digital production, markets and societies in general, and their impacts extend all the way to strategic issues at national economies levels. So further research spanning over many domains is expected in the future, and it is supposed that the contributions presented in this paper will provide useful inputs for these efforts.

\section{Acknowledgements}

The author acknowledges the support of the Slovenian Research Agency ARRS through research program Pervasive computing.

\section{References}

Affairs, D. of E. and S. (2020). E-Government Survey 2020. United Nations.

Annarelli, A., Battistella, C., \& Nonino, F. (2019). What is a Product Service System? In The Road to Servitization: How Product Service Systems Can Disrupt Companies' Business Models (pp. 1-29). Springer International Publishing. https://doi.org/10.1007/978-3-030-12251-5_1

Basole, R. C. (2019). On the Evolution of Service Ecosystems: A Study of the Emerging API Economy. In P. P. Maglio, C. A. Kieliszewski, J. C. Spohrer, K. Lyons, L. Patrício, \& Y. Sawatani (Eds.), Handbook of Service Science, Volume II (pp. 479-495). Springer International Publishing. https://doi.org/10.1007/978-3-319-985121 21

Berlind, D. (2019). 8 Real World API Strategies and The Keys to Their Success.

Bettendorf, M. (2021). Postman blog. https://blog.postman.com/api-growth-rate/

Bureau, U. S. C. (2021). API examples.

Castro, C., \& Lopes, C. (2021). Digital Government and Sustainable Development. Journal of the Knowledge Economy. https://doi.org/10.1007/s13132-021-00749-2

Distel, B., \& Lindgren, I. (2019). Who Are the Users of Digital Public Services? In P. Panagiotopoulos, N. Edelmann, O. Glassey, G. Misuraca, P. Parycek, T. Lampoltshammer, \& B. Re (Eds.), Electronic Participation (pp. 117-129). Springer International Publishing.

Eckert, T., \& Hüsig, S. (2021). Innovation portfolio management: a systematic review and research agenda in regards to digital service innovations. Management Review Quarterly. https://doi.org/10.1007/s11301-02000208-3

Eggrickx, B., Lefort, M., \& Roset, A. (2020). Blockchain and Postal Digital Services: Opportunities and Drawbacks. In P. L. Parcu, T. J. Brennan, \& V. Glass (Eds.), The Changing Postal Environment: Market and Policy Innovation (pp. 151-165). Springer International Publishing. https://doi.org/10.1007/978-3-030-34532-7_12

Fang, Z., Joseph, W., \& Mohini, S. (2015). E-government development and the digital economy: a reciprocal relationship. Internet Research, 25(5), 734-766. https://doi.org/10.1108/IntR-02-2014-0055

Forrester, J. W. (1994). System dynamics, systems thinking, and soft OR. System Dynamics Review, 10(2-3), 245256. https://doi.org/https://doi.org/10.1002/sdr.4260100211

Forum on tax administration, -. (2019). Unlocking the digital economy - A guide to implementing application programming interfaces in government. OECD LK - https://cutt.ly/Pngo6hN.

Frank, A. G., Mendes, G. H. S., Ayala, N. F., \& Ghezzi, A. (2019). Servitization and Industry 4.o convergence in the digital transformation of product firms: A business model innovation perspective. Technological Forecasting and Social Change, 141, 341-351. https://doi.org/https://doi.org/10.1016/j.techfore.2019.01.014

Gagliordi, N. (2019). IoT to drive growth in connected devices through 2022: Cisco.

Gonzalez, J., \& Tr\vcek, D. (2017). Proper Incentives for Proper IT Security Management - A System Dynamics Approach. HICSS. 
Hernantes, J., Labaka, L., Lauge, A., Sarriegi, J., \& Gonzalez, J. (2012). Group model building: A collaborative modelling methodology applied to critical infrastructure protection. Int. J. of Organisational Design and Engineering, 2, 41-6o. https://doi.org/10.1504/IJODE.2012.045904

Higginbotham, J. (2015). Designing Great Web APIs (1st ed.). O’Reilly Media, Inc.

Immonen, A., Ovaska, E., \& Paaso, T. (2018). Towards certified open data in digital service ecosystems. Software Quality Journal, 26(4), 1257-1297. https://doi.org/10.1007/s11219-017-9378-2

Itten, R., Hischier, R., Andrae, A. S. G., Bieser, J. C. T., Cabernard, L., Falke, A., Ferreboeuf, H., Hilty, L. M., Keller, R. L., Lees-Perasso, E., Preist, C., \& Stucki, M. (2020). Digital transformation-life cycle assessment of digital services, multifunctional devices and cloud computing. The International Journal of Life Cycle Assessment, 25(10), 2093-2098. https://doi.org/10.1007/s11367-020-01801-o

Izhutov, P., \& Mendelson, H. (2019). Pricing a Digital Services Marketplace Under Asymmetric Information. In J. Miller, E. Stroulia, K. Lee, \& L.-J. Zhang (Eds.), Web Services -- ICWS 2019 (pp. 12-25). Springer International Publishing.

Jarke, J. (2021). Co-Creating Digital Public Services. In Co-creating Digital Public Services for an Ageing Society: Evidence for User-centric Design (pp. 15-52). Springer International Publishing. https://doi.org/10.1007/978-3-030-52873-7_3

Jin, B., Sahni, S., \& Shevat, A. (2018). Designing Web APIs: Building APIs That Developers Love (1st ed.). O’Reilly Media, Inc.

Kulkarni, A., \& Dambe, S. (2020). Innovating Digital Consumer Services in Wealth Management Ecosystem an Anthropomorphic Approach. In M. Tuba, S. Akashe, \& A. Joshi (Eds.), Information and Communication Technology for Sustainable Development (pp. 249-257). Springer Singapore.

Maheepala, S. D. S. R., Warnakulasooriya, B. N. F., \& Weerakoon Banda, Y. K. (2018). Measuring Servitization BT Practices and Tools for Servitization: Managing Service Transition (M. Kohtamäki, T. Baines, R. Rabetino, \& A. Z. Bigdeli, Eds.; pp. 41-58). Springer International Publishing. https://doi.org/10.10o7/978-3-319-76517-4_3

Marciniak, R., Moricz, P., \& Baksa, M. (2020). Towards Business Services 4.o - Digital Transformation of Business Services at a Global Technology Company. In I. Oshri, J. Kotlarsky, \& L. P. Willcocks (Eds.), Digital Technologies for Global Sourcing of Services (pp. 124-144). Springer International Publishing.

Markets, R. \&. (2017). Application Programming Interfaces (API) in Telecommunications and Internet of Things (IoT): Market Outlook and Forecasts for Telecom and IoT APIs 2017 - 2022 - Research and Markets.

Musser, J. (2013). API Business Models, ProgrammableWeb.

Natain, R., Merril, A., \& Lesser, E. (2016). Evolution of the API Economy.

Pongtanalert, K., \& Ogawa, S. (2015). Classifying user-innovators - An approach to utilize user-innovator asset. Journal of Engineering and Technology Management, 37, 32-39. https://doi.org/https://doi.org/10.1016 /j.jengtecman.2015.08.005

Porter, D. E. (1962). Industrial Dynamics. Jay Forrester. M.I.T. Press, Cambridge, Mass.; Wiley, New York, 1961. xv + 464 pp. Illus. \$18. Science, 135(3502), 426-427. https://doi.org/10.1126/science.135·3502.426-a

Raconteur. (2017). API Ecosystems, Digital Transformation Special Report.

Rodríguez de las Heras Ballell, T. (2021). The background of the Digital Services Act: looking towards a platform economy. ERA Forum. https://doi.org/10.1007/s12027-021-00654-w

Romero, D., Gaiardelli, P., Pezzotta, G., \& Cavalieri, S. (2019). The Impact of Digital Technologies on Services Characteristics: Towards Digital Servitization. In F. Ameri, K. E. Stecke, G. von Cieminski, \& D. Kiritsis (Eds.), Advances in Production Management Systems. Production Management for the Factory of the Future (pp. 493-501). Springer International Publishing.

Rothgang, M., \& Dürig, W. (2020). The Changing Role of SMEs in Innovation Activities in Germany--The Example of the Automobile Value-Added Chain. In A. Oberheitmann, T. Heupel, Y. Junqing, \& W. Zhenlin (Eds.), German and Chinese Contributions to Digitalization: Opportunities, Challenges, and Impacts (pp. 253-267). Springer Fachmedien Wiesbaden. https://doi.org/10.1007/978-3-658-29340-6_18

Sabri, Y., Micheli, G. J. L., \& Nuur, C. (2018). Exploring the impact of innovation implementation on supply chain configuration. Journal of Engineering and Technology Management, 49, 60-75. https://doi.org/https://doi.org/10.1016/j.jengtecman.2018.06.oo1

Schneider, D., Klumpe, J., Adam, M., \& Benlian, A. (2020). Nudging users into digital service solutions. Electronic Markets, 30(4), 863-881. https://doi.org/10.1007/s12525-019-00373-8

Senshaw, D., \& Twinomurinzi, H. (2020). Designing for Digital Government Innovation in Resource Constrained Countries: The Case of Woredas in Ethiopia. In S. Hofmann, O. Müller, \& M. Rossi (Eds.), Designing for Digital Transformation. Co-Creating Services with Citizens and Industry (pp. 42-55). Springer International Publishing.

Shaikh, A. A. (2019). Identifying Critical Determinants of 'Digital Customer Services' Usage -- An Exploratory Study. In F. J. Martínez-López, J. C. Gázquez-Abad, \& A. Roggeveen (Eds.), Advances in National Brand and Private Label Marketing (pp. 190-196). Springer International Publishing. 
Sun, H. (2019). Evolution of Digital Music Services. In Digital Revolution Tamed: The Case of the Recording Industry (pp. 97-134). Springer International Publishing. https://doi.org/10.1007/978-3-319-93022-0_4

Tomanek, D. P., Hufnagl, C., \& Schröder, J. (2020). Determining the Digitalization Degree of Information Flow in the Context of Industry 4.o Using the Value Added Heat Map. In A. Kolinski, D. Dujak, \& P. GolinskaDawson (Eds.), Integration of Information Flow for Greening Supply Chain Management (pp. 159-179). Springer International Publishing. https://doi.org/10.1007/978-3-030-24355-5_10

Trcek, D. (2018). Trust and reputation management systems: an e-business perspective. Springer. https://doi.org/10.1007/978-3-319-62374-o

Tuomi, A., Tussyadiah, I., \& Ashton, M. (2021). Covid-19 and Instagram: Digital Service Innovation in Top Restaurants. In W. Wörndl, C. Koo, \& J. L. Stienmetz (Eds.), Information and Communication Technologies in Tourism 2021 (pp. 464-475). Springer International Publishing.

Vaccari, L., Posada Sanchez, M., Boyd, M., Gattwinkel, D., Mavridis, D., Smith, R., Santoro, M., Nativi, S., Medjaoui, M., Reusa, I., Switzer, S., \& Friis-Christensen, A. (2020). Application Programming Interfaces in Governments: Why, what and how. Publications Office of the European Union.

Vassilakopoulou, P., \& Hustad, E. (2021). Bridging Digital Divides: a Literature Review and Research Agenda for Information Systems Research. Information Systems Frontiers. https://doi.org/10.1007/s10796-020-10096-3

Walters, D., \& Helman, D. (2020). Partnerships: Managing Intra- and Interorganizational Relationships -- The Global Value Chain Network. In Strategic Capability Response Analysis: The Convergence of Industrié 4.0, Value Chain Network Management 2.0 and Stakeholder Value-Led Management (pp. 195-219). Springer International Publishing. https://doi.org/10.1007/978-3-030-22944-3_8

Westerman, G., Bonnet, D., \& McAfee, A. (2014). The Nine Elements of Digital Transformation. In MIT Sloan Management Review. MIT Publishing.

Wittern, E. (2018). Web APIs - Challenges, Design Points, and Research Opportunities: Invited Talk at the 2nd International Workshop on API Usage and Evolution (WAPI '18). Proceedings of the 2nd International Workshop on API Usage and Evolution, 18. https://doi.org/10.1145/3194793.3194801

$\mathrm{Xu}, \mathrm{L}$. Da, Xu, E. L., \& Li, L. (2018). Industry 4.o: state of the art and future trends. International Journal of Production Research, 56(8), 2941-2962. https://doi.org/10.1080/00207543.2018.1444806

Zaramenskikh, E., \& Lyubarskaya, M. (2020). Integration of Digital Services Within the Framework of the Implementation of "Government as a Platform" (GaaP) Model on the Example of a Social Fund. In E. Zaramenskikh \& A. Fedorova (Eds.), Digital Transformation and New Challenges (pp. 1-10). Springer International Publishing.

Zhang, N., Zhao, X., \& He, X. (2020). Understanding the relationships between information architectures and business models: An empirical study on the success configurations of smart communities. Government Information Quarterly, 37(2), 101439. https://doi.org/https://doi.org/10.1016/j.giq.2019.101439

Zygiaris, S. (2021). The Impact of Innovation Systems on E-commerce Capacity. Journal of the Knowledge Economy. https://doi.org/10.1007/s13132-021-00724-x 